\title{
Correction: Continuous Monitoring of Vital Signs Using Wearable Devices on the General Ward: Pilot Study
}

Mariska Weenk ${ }^{1}$, MD; Harry van Goor $^{1}, \mathrm{MD}, \mathrm{PhD}$, FRCS; Bas Frietman ${ }^{1}$, MD; Lucien JLPG Engelen ${ }^{2}$; Cornelis JHM van Laarhoven ${ }^{1}$, MD, PhD, MSc; Jan Smit ${ }^{3}$, MD, PhD; Sebastian JH Bredie ${ }^{3}$, MD, PhD; Tom H van de Belt ${ }^{2}$, $\mathrm{PhD}$

${ }^{1}$ Radboud University Medical Center, Department of Surgery, Nijmegen, Netherlands

${ }^{2}$ Radboud University Medical Center, Radboud REshape Innovation Center, Nijmegen, Netherlands

${ }^{3}$ Radboud University Medical Center, Department of Internal Medicine, Nijmegen, Netherlands

\section{Corresponding Author:}

Mariska Weenk, MD

Radboud University Medical Center

Department of Surgery

P.O. Box 9101

Nijmegen, $6500 \mathrm{HB}$

Netherlands

Phone: 31243611111

Fax: 31243635115

Email: mariska.weenk@ radboudumc.nl

\section{Related Article:}

Correction of: https://mhealth.jmir.org/2017/7/e91/

(JMIR Mhealth Uhealth 2021;9(7):e31899) doi: 10.2196/31899

In "Continuous Monitoring of Vital Signs Using Wearable Devices on the General Ward: Pilot Study" (JMIR Mhealth Uhealth 2017;5(7):e91), one error was noted.

In the originally published manuscript, an incorrect ORCID number was listed for author Jan Smit. This ORCID number has now been removed.
The correction will appear in the online version of the paper on the JMIR Publications website on July 16, 2021, together with the publication of this correction notice. Because this was made after submission to PubMed, PubMed Central, and other full-text repositories, the corrected article has also been resubmitted to those repositories.

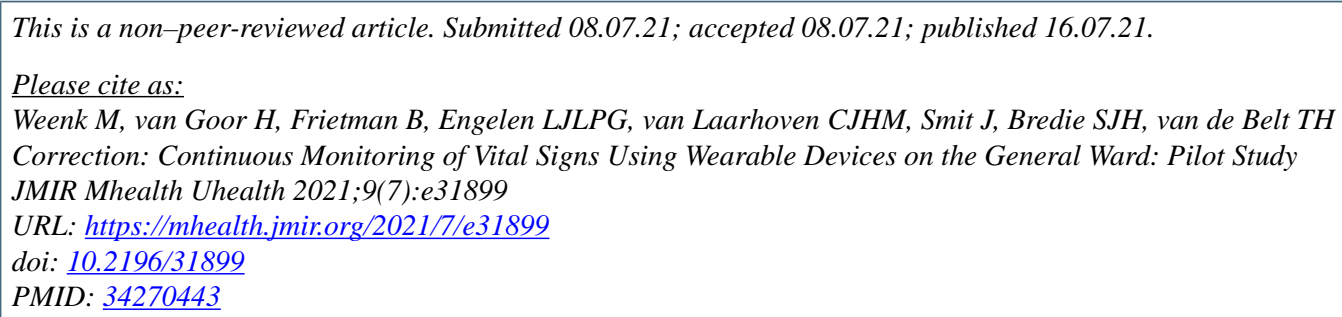

CMariska Weenk, Harry van Goor, Bas Frietman, Lucien JLPG Engelen, Cornelis JHM van Laarhoven, Jan Smit, Sebastian JH Bredie, Tom H van de Belt. Originally published in JMIR mHealth and uHealth (https://mhealth.jmir.org), 16.07.2021. This is an open-access article distributed under the terms of the Creative Commons Attribution License (https://creativecommons.org/licenses/by/4.0/), which permits unrestricted use, distribution, and reproduction in any medium, provided the original work, first published in JMIR mHealth and uHealth, is properly cited. The complete bibliographic information, a link to the original publication on https://mhealth.jmir.org/, as well as this copyright and license information must be included. 